\title{
Metamethodology and Historiography: Towards a Consistent Empirical Genetic World View
}

\author{
Hayo Siemsen 1,2,3 \\ ${ }^{1}$ Ernst Mach Institut für Erkenntnistheorie \\ ${ }^{2}$ University of Education, Heidelberg, Germany \\ ${ }^{3}$ Masaryk University, Brno, Czech Republic \\ Email: hayo.siemsen@gmail.com
}

Received 1 April 2015; accepted 16 April 2015; published 7 May 2015

Copyright (C) 2015 by author and Scientific Research Publishing Inc.

This work is licensed under the Creative Commons Attribution International License (CC BY). http://creativecommons.org/licenses/by/4.0/

\section{(c) (i) Open Access}

\begin{abstract}
Are there many methodologies and many historiographies, or is there in principle just one science? Basically, there are only two sources of knowledge: empirical (sensual) experience and metaphysical assumptions. Unfortunately, the two are often difficult to distinguish, especially because all methodologies and historiographies make a different "frame" of assumptions, basic concepts with different empirical meanings, relations, etc. How can all this be reconciled? The following article will argue that the confusion has indeed very old roots, but that as soon as those roots are laid open, it is possible to use an alternative "meta-methodology", a worldview, which allows identifying arbitrary $a$ priori assumptions and form a common basis for consistently combining different methods. As a result, the methods cannot only check and reduce the systematic errors necessarily included in each method by itself, but combine methods in a meaningful way in order to tackle scientific questions, which would be too speculative to pursue from the perspective of just one method. Applying an empirical genetic metamethodology additionally improves learning and applying science severalfold in terms of effectiveness and efficiency.
\end{abstract}

\section{Keywords}

Empirical Genesis, Ernst Mach, Metamethodology, Historiography, Gestalt, Sensualism

\section{Introduction}

It would seem that science has many methodologies and history has many historiographies ${ }^{1}$. Strangely though,

${ }^{1}$ For a more detailed discussion of historiographical questions and connections especially to Koselleck and his successors, see Siemsen (2009). 
many of these appear to be inconsistent or even contradictory. But they belong to science (science here understood as all of science, not just the natural sciences, including philosophy, history, psychology, education, social sciences, etc.). And there is a reason, why one calls "science" in such a way, i.e. as "one". "Science" can and must of course have different perspectives from which to view phenomena. But plurality of perspectives (on William James' Mach-inspired idea of "pluralism", see later) does not imply that this makes them different phenomena, nor that one can epistemologically "cut" phenomena into neatly separable pieces. This would destroy their "inner structure" (as the gestalt theorist Max Wertheimer, see Luchins 1975, has argued, see also Wertheimer, 1924/1938).

So why are there these seeming inconsistencies within science and between science and general human knowledge? Is there a way to avoid contradictions, of knowledge and science becoming "one"? Yes there is, and the method to this is actually quite old. At least some 1800 years old, if not older. It is the "empirical genetic" method $^{2}$. It provides a "meta-methodology", which can combine different methods. Metamethodology actually requires different methods and a common "bond" in order to join their strengths and cancel out their systematic weaknesses. But before this can be elaborated in detail, some general conceptual questions need to be clarified: what is knowledge, what is science and what is "meta-method"? The concepts used here have quite different empirical meanings from their usual usage, so this "shift" needs to be addressed beforehand.

\subsection{What Is Human Knowledge and Scientific Knowledge as Part of It?}

The first question is: what is human knowledge and scientific knowledge as part of it? Fundamentally, there are only two ways of acquiring knowledge: through (sensual) experience and through (cultural) transmission from the "forefathers", the "ancients", or the "god(s)". The transmitted knowledge might be part of experience by the previous generations. Though very often, they did not clearly distinguish between what they experienced with their senses and what they (metaphysically) added to that by imagination, revelation, etc. As a result, the experiential (empirical) part and the metaphysical part of knowledge are seemingly inextricably intertwined. This happens on many levels, which makes any attempt at resolving such genetic knots very difficult. Therefore, many researchers have suggested that solving a Gordic knotwork is impossible anyway and therefore we will never know. But a difficult task requires maybe new approaches, not an "ignorabimus". This article will show that such an approach is quite possible and even necessary for scientific development as well as understanding science. As history suggests, Gordic knots can be resolved, though it might require alternative approaches ${ }^{3}$.

\subsection{What Is Science?}

The second question is: what is science? Science in the sense used here is simply about "knowing the world", including human psychology. Nothing more and nothing less. It is not about particle accelerators (at least not primarily). It is what every human (and many "other" animals) do, namely getting to know the world. It is just "refined" in that one tries to develop specific methods of thought, which help in this process. This "meta-perspective" on knowledge creation is what makes it somewhat different to everyday thinking (see Mach, 1905). But this is only a matter of degree, not of principle (no metaphysical assumption of a separate faculty of "reason" is necessary). There are fundamentally only two criteria for science and scientific knowledge: its consistency with the facts and its internal consistency (or as Ernst Mach, 1905, put it "the adaptation of the thoughts to the facts and the thoughts to each other").

\subsection{What Is a "Meta-Method"?}

The third question is: what is a "meta-method"? "Empirical genesis" is not a method in a classical sense. It is a meta-method or erkenntnis-theory (from the German Erkenntnistheorie, i.e. close to the meanings of "theory of knowledge" by William James, epistemology or theory of cognition). It is a worldview—not a theory in the

\footnotetext{
${ }^{2}$ Different forms of "empirical genesis" have never been historically called in such a way. Certain forms of empiricism belong to it, though the method is more general. "Genesis" can in a similar way be seen as a more general form of "history". The method is thus not new, but it has never been identified as a singular method with specific common elements.

${ }^{3}$ It is probably not by chance that Alexander the Great presumably "resolved" the Gordic knot after being taught the empirical genetic method of learning by Aristotle. Unfortunately, little is known about how Aristotle proceeded, but some typical educational phenomena can be observed in Alexander's way of thinking (erkenntnis-theory).
} 
classical sense. Worldviews provide not primarily a "fixed" conceptual frame, but only the common standpoint from which all empirical meanings of concepts are "exchanged". Then only as a result of the exchange, they indirectly provide the basic conceptual "frame" (erkenntnis-theory). This frame includes the pre-scientific concepts, which intuitively shape this "frame" (erkenntnis-theory is thus reciprocal, which often leads to conceptual confusions, such as the distinction between "ontological" and "epistemological"). In principle, there are only two world views known: The empirical world view and the metaphysical world view. Depending on which part of human knowledge one "prefers" or "takes as the standard measure", one uses the one or the other.

Most people unknowingly use combinations of the two world views. The result is a muddle, which produces many inconsistencies (often then called "puzzles"). If one uses the metric system and the British Imperial system of measures or the United States customary unit system jointly in some venture, such as sending a rocket to space, one might crash the rocket because of the (numerical) inconsistencies, which are often difficult to avoid. But these are still "empirical" systems of measurement, which can in principle be transformed into one another. It becomes more difficult, the more metaphysics becomes involved and the systems becoming more complex. If, for instance, one would use a Newtonian system of physics in order to fly to the moon, one would crash on it. Not because of some calculation error, but because of some basic assumptions, which appear empirical, but which are empirically false. The errors in a system of separate (and independent) space and time concepts relative to spacetime concepts become too large for a safe landing.

Newton unquestioningly took the assumption (hypothesis) on of absolute and independent space and time from ancient sources. Already Zoroaster describes that Ahura Mazda (the "one" god) in the beginning of the world created two spirits, the spirit of space and the spirit of time ${ }^{4}$. These spirits then start fighting each other over the dominance of the world. The brother-conflict/dualist good-evil story makes the implicit assumption that time and space are separate entities. This hypothesis is then integrated into ancient Greek scientific thought by Pythagoras (who had strong influences by "eastern” religious speculation), then by Parmenides in his philosophy, who explicitly abstracts the time dimension (becoming) from "being". Plato and his Academy integrate the hypothesis further into their philosophical framework, for instance by introducing the holistic concept of "form" or "species", explicitly independent of its "process", i.e. the time dimension. Platonist duality, as Descartes and Newton adopt, is based on the metaphysical assumption of separate space and time. This assumption, as we now know, is empirically false. It is not a matter of metaphysics (anymore), but of facts, which—if considered consistently—lead to a "falsification" of dualism (and all the metaphysics built on it). Nevertheless for the purpose of this article, it is sufficient to reject the Platonian conceptual frame for the purpose of scientific method. The argument shows, why changing one's world view is so difficult, even if one-as in the case of William James-deliberately wants to change it.

\section{Pluralism vs. Genesis}

Currently, ideas of "pluralism" are en vogue in several sciences, such as economics. Metamethodology is similar in a way. William James developed his idea of pluralism from empirical genetic roots which he found in Mach's Erkenntnis und Irrtum (1905; knowledge and error, see also Siemsen, 2014) ${ }^{5}$. While James’s approach is holistic, i.e. still Platonist in important aspects, Mach's is genetic, i.e. it consistently integrates the time dimension (spacetime, see Einstein, 1916). James (Thiele, 1978: pp. 169/173) admitted to Mach in having trouble understanding and implementing the genetic issues from Mach:

"I am now trying to build up before my students a sort of elementary description of the construction of the world as built up of 'pure experiences' related to each other in various ways, which are also definite experiences in their turn. 'There is no logical difficulty in such a description to my mind, but the genetic questions concerning it are hard to answer.' I wish you could hear how frequently your name gets mentioned, and your books referred to.”

This de facto omission of genetic issues because of the difficulties James had with them unfortunately creates an inconsistency in James' approach on pluralism. It is thereby not possible for pluralism to integrate different

\footnotetext{
${ }^{4}$ The interpretation of the spirits of good and evil as time and space might not have been from Zoroaster himself, but a synthesis with other sources connected to "Zurvan" a god of time. The example here is only to show that the conceptual separation of time and space has been around seemingly for a while in different cultures.

${ }^{5}$ Erkenntnis und Irrtum is by far the most hand-annotated book in James’ library at Harvard. James worked very intensively on the ideas contained in it, but unfortunately did not live long enough anymore in order to produce a new consistent version. His Radical Empiricism has to be considered as the second step in this direction (Pragmatism being the first).
} 
perspectives. Even worse, the approach tends to abstract from empiry and thereby becomes arbitrary (metaphysical) and non-scientific ${ }^{6}$.

Why is the abstraction from the genetic approach an "error"? This is a corollary of the time dimension of evolutionary processes. Evolutionary growth processes start seemingly small. The "first time" has to be "successful". This is a tedious and seemingly "slow" process, involving many potential errors. Replication of a once successful process is seemingly "faster". The supposed "speed" of the process is nevertheless misleading. If one plants the (small) seed of a tree, in the beginning, it seems to grow only slowly (maybe a few centimeters in a year) relative to human size, while relative to the size of the seed, it grows very fast (doubling, tripling the size relative to the initial size of the seed). Thus, the "slowness" is only relative to the size of the observer, not to its inherent size.

Developing an idea from Aristotle further, Alexander of Aphrodisias (200/2014: p. 38) notes that this principle applies to basically all growth processes in nature,

"What is responsible for the proportional difference between [the soul of unanimated nature, plants, animals and humans] is the difference in the bodies underlying them, as regards their number as well as the particular kind of blend, mixture and formation. And that makes sense. For if 'the beginning (arkhê) is not just part [as Aristotle writes], but the largest part of the whole', then it makes sense that a difference in the origins (kata tas arkhas), even if small can be responsible for a great difference. This is obvious from the forks in roads too. For a small disparity between them is often responsible for a great distance from each other. But the proximate matter [circumstances of facts] of each thing that comes to be is also an origin. So it makes sense that the difference in forms that comes on top of differences in the proximate matter actually results from them. For not all matter [though very similar in Gestalt] can receive the same culmination.

If someone on first hearing thinks it incredible that the soul is this sort of body's form and nature, [...] but then looks at the distinction between the bodies that have these forms and sees how unspeakably greater the construction of animate bodies is than that of simpler bodies, [he would not find it incredible] to say that the proportion that the bodies underlying the forms have to one another is the same as the one that their forms preserve to each other [i.e. phylogenie and ontogenie].”

Here, Alexander inherently switches the idea of growth processes from a linear model to an exponential model (he explicitly goes beyond Aristotle in this). Small initial differences might, by frequent repetition, lead to large differences later in the process. This of course often distracts from looking more closely into the initial differences, while being astonished by the later ones ${ }^{7}$.

\subsection{The Linear and Exponential Learning Model}

According to Mach $(1863,1905)$, also human knowledge processes and scientific knowledge processes are evolutionary growth processes in Alexander's sense.

Figure 1(a) shows the "standard" linear model of a learning process. The time "consumed" per unit learned is $\Delta \mathrm{t}$. Then there is a longer break, such as a summer break (arrêt). If one now wants to resume learning after the break, one would assume to restart where one left off. But empirically, this is not so. After $\Delta$ tm much contents is forgotten (Semon area). By repeating the exam from before the break without preparation, one typically finds only $10 \%-20 \%$ of the knowledge (subtracting what was there already initially before teaching). It is correct that some of this "forgotten" contents can be relearned faster than before, but it has to be relearned. Then it is forgotten again.

When one ignores this memory effect in linear learning and starts at the old learning level $\Delta \mathrm{tm}$, some "laggards" are left behind (students who cannot close the memory gap by themselves). But this is not the biggest error. The undefined starting point makes a higher contribution. No care is taken of testing the kind of pre-knowledge or intuition. This start makes two tacit assumptions: that nothing is forgotten and that no pre-knowledge is required for axioms. But axiomatic generalizations, like for instance those that Hilbert made in geometry, require a high experience and intuition of pre-concepts (see Hadamard, 1945).

${ }^{6}$ This is a problem of jumping from the observation that there is a need for many different methods to the conclusion that method is arbitrary and does not matter. Unfortunately, such an error can nowadays be found in the methodological assumptions for instance of many social scientists. Even if one takes an enlarged view on what empiry is, it still matters what is empirical. There is no arbitrariness in freedom of thought, but clarity and precision (see also Peirce' 1878 foundational article on Pragmatism "How to make our ideas clear"). Only metaphysics may be considered arbitrary in a way (several manyfolds might be possible, i.e. internally consistent but undecidable), but this can only be decided after distinguishing very clearly between what is empirical and what is metaphysical.

7"Already antique philosophers sensed [the thought of Darwin] by turning their amazed view from the wondrous abundance of developed living nature to the more simple developing and slightly more sobered turning their view back.” (Mach, 1909: p. 2) 


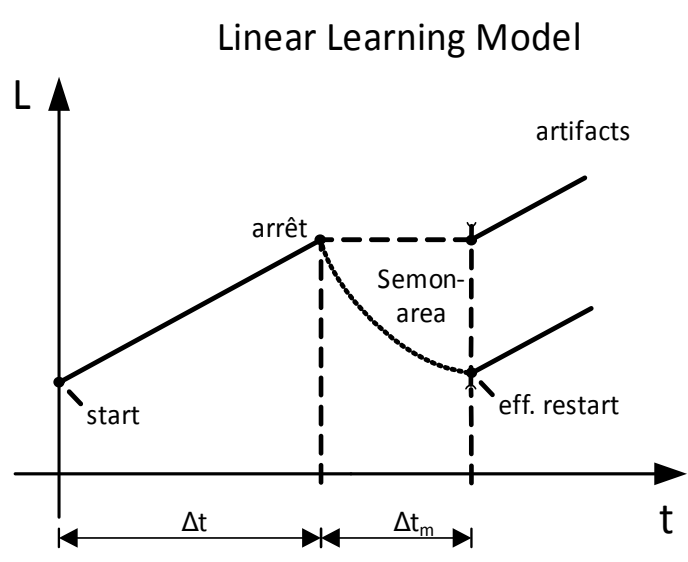

(a)

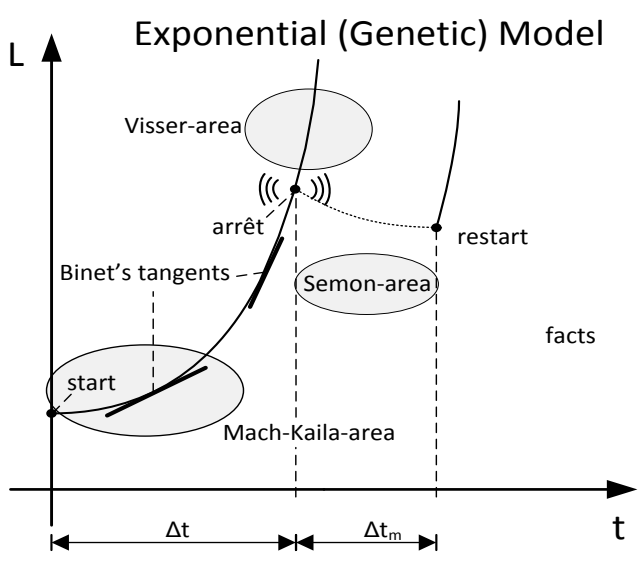

(b)

Figure 1. (a), (b) Linear learning model vs. exponential learning model (see Siemsen, 2013).

No wonder that as a result, learning is reduced to consuming a well defined lesson contents with no relation to Gestalt psychology, psychophysics, erkenntnis-theory or transfer to other contents. As science produces more and more contents, there is a contents "overflow" defined by curricula with more and more precise defined static contents. The relation between these contents in different areas is thereby neglected by the curricula.

This problem is resolved by an exponential model (Figure 1(b)).

How do growth processes in nature work? Plants and animals in principle grow (and multiply) exponentially. Malthus even made the point for humans. If one considers human knowledge (and scientific knowledge as part of it) as part of evolutionary processes (see for instance Mach 1883/1888), there is no reason, why learning should not work exponentially. Actually it does so, if one removes all the "obstacles", which hinder this exponential process (such as the obstacles produced by a Pythagorean/Platonian world view).

Figure 1(b) shows a graphic exponential model of learning. An exponential learning curve has (maximum) two intersections with a linear learning curve. If the learning time is long enough, the exponential function will necessarily win (overtake the linear curve). But the educational gut feeling of nearly everybody will tell: exponential learning consumes much more time. When implementing learning the Ramus-Comenius-Mach-Kaila way (which gives room for Gestalt processes, psychophysics and erkenntnis-theory and seems to "crawl" along extremely slow), the gut feeling tends to be dominant in time perception.

In an experimental arrangement one can give exactly the same time $\Delta t$ as in the linear model. The statistical impact of the Mach-Kaila model and the exponential slope will correct the gut feeling. At the arrêt, one can even measure transfer to other contents. The slope of the tangents to the exponential function of learning was found experimentally by Alfred Binet (the inventor of the intelligence scale) during experiments between 1907 and 1910 after he had a discussion with Mach (see Vaney, 1911; Siemsen, 2010a).

\subsection{Educational Corollaries of the Exponential Learning Model}

The insight from Alexander of Aphrodisias has an important methodological implication: if the origin determines the later development to a larger degree (more than $50 \%$, i.e. maybe $70 \%-80 \%$ ), also the research needs to be focused on this area. Any mistake included in this "beginning" will have much more consequences than any later mistake or time spent on later details. In terms of learning, the "Mach-Kaila-area" is especially prone to any mistake in the genesis process.

This can, for instance, be observed in the learning by the Montessori method. Maria Montessori uses partly genetic processes, but not consistently. So the exponential learning process tends to frequently break down, although beginnings of it can often be observed (for instance in her mathematical material). Montessori herself learnt her erkenntnis-theory from her teacher Jakob Moleschott. Moleschott already presumed many ideas about ten years before Darwin published them in his "Origin" in 1859, but he did not make a consistent reevaluation of spacetime. So for instance on the one hand, Moleschott criticizes Plato's ideal ideas (and the scala naturae) as metaphysical, promoting sensualism instead. On the other hand, Moleschott sees matter as "undying", i.e. time- 
less. Matter has only spatial qualities, but no time (see for instance Moleschott, 1852). Moleschott died shortly after Montessori became his student in Rome (in physiology as part of her medical studies) ${ }^{9}$. Montessori herself later on tried to work on this inconsistency. Unfortunately, the successors of Montessori did not notice the error and did not work on consistently and empirically reducing the mistakes in the genesis process. Furthermore, erkenntnis-theory is not explicitly taught to the students, so they cannot in general optimize the process themselves. As a result, one can observe the process breaking down again and again, often before consistent gestalts are formed.

Concerning metamethodology and historiography, the genetic question is therefore the most important one. Of course, one can focus on the "other" $20 \%$ - 30\% of the process, but with any methodological mistake in the origin/arkhê, everything else seems a waste of time and resources. In education, Hattie $(2009,2012)$ has collected an impressive list of such "artifacts": 60,000 empirical quantitative studies on education, which basically all observe only linear learning effects. Relative to the improvements possible with exponential learning (500\% $1000 \%)$, "small" improvements of even 50\% seem like a waste of time. Nevertheless, many researcher argue that they prefer to continue in this direction, because they have already invested so much time into it. Otherwise, they would need to completely "rethink". Such a view has little to do with scientific methodology. Why such reaction? They are presumably stuck in the "Platonic cage" (see Siemsen, 2015), which makes a fundamental rethinking difficult, because it makes it difficult to decide, what is empirical, i.e. necessary from experience, and what is metaphysical, i.e. arbitrary in thinking.

\subsection{The Historical Origins of the Metaphysical and the Empirical World View}

In principle there are only two world views, the empirical world view and the metaphysical world view. The "metaphysical" world view appears first explicitly with Pythagoras. It was then developed into an elaborate system by Plato (see Siemsen, 2015). The metaphysical world view is fundamentally based on religion, i.e. religious assumptions about the (eternal life of a) "soul" and a scala naturae, i.e. the assumption that humans must be different from other living beings and that this difference is something they share with the gods ${ }^{10}$. What humans supposedly share with the gods is the faculty of "reason". "Reason" enables humans to find the "ideal ideas", i.e. godly and eternal ideas ${ }^{11}$. Following Plato, the most important knowledge, therefore, is not the knowledge derived from the (lower and animal-like) senses. Such knowledge should be rather avoided, because the senses are fundamentally misleading. Godly knowledge instead can only be gained by the initiation to "godly ideas". As the ideas are eternal (transcendental, i.e. they "transcend" the limitations of worldly knowledge), they can be used a priori without further discussion, as they are "apodictic" (in order to use Kant's terminology for the Platonic world view).

Such an approach is unfortunately not only empirically false, it is also detrimental for mental flexibility. As already the gestalt psychologists Luchins \& Luchins (1959) described, a priori frames lead to conceptual rigidity, as the basis of the assumptions are not known or not considered anymore and thus cannot be adapted, but only taken completely or rejected in totality. After investing much time into the Platonic world view, it becomes a methodological cage for one's thoughts.

The alternative "empirical" world view already implicitly exists in the Pre-Socratic natural philosophers, such as Thales ${ }^{12}$. It was elaborated by Aristotle, though he was still very influenced by Plato. Thereby Aristotle intro-

\footnotetext{
${ }^{8}$ The idea that matter was eternal (timeless) is quite old and already was postulated for instance by the Babylonians. Similar metaphysical assumptions are at the a priori basis of many materialist and physicalist theories. Planck attacked Mach on the ground of having found the physics "of all times". Unfortunately, at the end of his life, Planck had to backtrack and note that the "all times" was only a few years and that the physical "constants" he wanted to use as a secure foundation of all times were probably not so constant over long times (see Siemsen, 2010b). Again the consistent integration of spacetime not only in physical equations, but also into its erkenntnis-theory and worldview is a difficult task with many erkenntnis-theoretical pitfalls. Mach knew this and warned of mistaking metaphysical artifacts as facts.

${ }^{9}$ Of course Montessori was using other sources for her pedagogical work, but the erkenntnis-theory provides the basic conceptual frame within which one finds and adapts such other works. Thus, the erkenntnis-theory is more fundamental and thereby often also more intuitive, i.e. more influential and not explicit. Einstein called this the "mother-milk" effect (which he observed for instance in the kind of influence Mach had, see Siemsen, 2015).

${ }^{10}$ Humans are thus god-like or at least can become like gods, if they acquire the "right” (i.e. Pythagorean/Platonist) ideas.

${ }^{11}$ Empirically, no faculty of reason exists a priori in humans (in pedagogical experiments). "Reason" appears only after a specific training of the method of thinking. It is an artifact of Plato's dialectic method, not a physiological fact as many people seem to assume (see Siemsen, 2015). Unfortunately, though Aristotle partly criticizes Plato's idealized concepts, he adopts that part of the metaphysics from Plato's Academy (as intellectus agens, see below).

${ }^{12}$ One can probably trace the empirical world view to the pre-Greek civilization of "old Europe", i.e. the culture developed in the Danube delta from around 7000 to 2000 B.C. (see Gimbutas, 1992, or Haarmann, 2011). This culture had a very pragmatic approach to developing technology by small improvements and adaptations. The results were spread throughout a non-hierarchic trading network. The connections to a "natural philosophy" view in ancient Greece still requires further detailed research.
} 
duced a mix of Platonian (e.g. scala naturae, godly rationality) and empirical ideas. For example Aristotle researches and uses "folk knowledge" sometimes too uncritically, without a thorough analysis of what might be empirical and what might be metaphysical in it (the distinction is easy to answer though). As a result, it is Alexander of Aphrodisias, who identifies the inconsistencies in Aristotle's empirical and metaphysical approaches. Alexander asks the question of separating them and usually takes the empirical approach as primary in cases of contradiction $^{13}$. Once empiry ${ }^{14}$ and metaphysics are separated, one can keep the metaphysics "flexible" and replace it more easily when it becomes necessary. The empirical becomes a stable basis of knowledge as everybody can (at least in principle) test any time. The separation is of course never final, but a process, the "time" dimension of genesis. Finalist statements are thereby metaphysical, even if claimed by empiricists.

Thus, Alexander of Aphrodisias identifies the importance of "genesis", and the "status nascendi" more than Aristotle. Kessler (2011) comments that, "Alexander had prefaced his psychology with the foundation of a natural philosophy without metaphysics. The intellectus agens loses its function in the context of the psychological process." Alexander of Aphrodisias thereby develops a consistent empirical view. This view disposes of the metaphysical scala naturae assumption and the Platonian "split" between a higher and a lower soul and the Platonian hypothesis of ideal ideas:

In terms of modern philosophy, the Platonic world view leads to a dualistic epistemological split between psyche and matter, while the empirical approach from Alexander of Aphrodisias remains monistic, seeing no fundamental, just a gradual difference between the psychical and the physiological.

\subsection{Adaptations and Transformations Based on Alexander of Aphrodisias' Views}

The views of Alexander were admittedly still rudimentary in many aspects and not followed consistently throughout. Nevertheless, the seeds continued to carry fruit in the long run and inspired many eminent thinkers. As the views seemed to diminish the role of god provided in Plato's system, many researchers in Muslim and Christian traditions saw Alexander critical, though tempting. Like Averroes (see Kessler, 2011), they tried to salvage the obviously relevant criticism of Plato's metaphysics without criticizing the role of god in philosophy at a time, when religion was overarching and politically defining the limits of scientific thought. Few dared openly to discuss Alexander, let alone cite him.

Nevertheless, the influence of the empirical world view initiated by Alexander continued and can be found implicitly in several traditions of thought. It led to the end of religious-based scholasticism and an empirical transformation of scientific thought (see Kessler, 2011 for some examples, there are probably many more). The first such influence (exemplary in the ideas of Averroes) was in El Andaluz until its demise through the Christian Reconquista. Then the ideas "moved" to Italy, namely the "free spirit" University of Padua. There they influenced Telesio, Pomponazzi, Zabarella (who developed a more genetic scientific methodology) and finally Cremonini (their empiricism has links to the likes of Bruno and Bacon). Issues of empiry versus metaphysics were at the centre. Cremonini seemingly discussed Alexander's empirical ideas intensively with his colleague Galileo (see letter in Muir, 2007). The ideas inspired by Alexander led to many new scientific and artistic ideas (see for instance Muir, 2007), which are subsumed under the name Italian Renaissance.

A third influence seemingly had an impact on Scots, especially including Scots and their students at the university in Paris, and later in the Netherlands, in Germany, England and especially in Scotland itself. The origin of this influence is still under research, but Alexander's ideas resurface with John Mair (maybe with Scotus, Occam and Buridan, but this is more obscure). It becomes obvious, because of Mair's connection to empiricism (see Broadie, 1985) and his influence on many concurrent philosophers and religious thinkers (as diverse as Loyola, the founder of the Jesuit Order, Calvin, Erasmus, John Knox and last but not least Petrus Ramus).

With Ramus, the ideas from Alexander of Aphrodisias take an important transformation, because with education the main tool of Plato's long-term influence to perpetuate his worldview finally becomes questioned. Ramus's approach is not yet explicitly genetic, but by questioning the classical way ideas are taught, he lays the basis for questioning their content as well. Also, with the methodological improvements in learning, ideas become accessible and questionable by in principle everybody, not just a small elite of (mainly church-based) scholars. This will be implemented systematically by Ramus' indirect student (through Alsted, see Hotson, 2007) Comenius. Comenius in his Great Didactics asks for the general education of everybody with everything (in

\footnotetext{
${ }^{13}$ This was maybe due to the recent rediscovery of Aristotle's library, to which Alexander might have had access.

${ }^{14}$ Empiry here is used in the German sense "Empirie" as opposite of metaphysics.
} 
principle only, but of course broad-based).

The above "history" necessarily remains sketchy. It is not meant as a detailed historical research here, but as exemplary of the scientific potential of the empirical genetic (meta)method.

\section{The Empirical Genetic Method as a Meta-Method}

The empirical genetic method in its methodologically fully developed version can then serve as a metamethodology. The empirical world view enables the exchange of the empirical meaning of concepts from all sciences. There are then general concepts, which work throughout different scientific fields (perspectives), different layers of history, etc. Other concepts might be specific for one scientific perspective, but can be made compatible through the common point of view. Just as a common currency serves as a means of exchange between many different types of goods, a metamethodology enables a broad possibility of exchanging concepts. Because the empirical meanings of the concepts are clear and the hypotheses and motives for them are laid open, one can at any time decide, if a concept is still valid and consistent or not (see for instance Beneke, 1842).

But the metamethodology goes one step further. Any method in science requires the development of a specific direction of thinking. Such training of thought might have the advantage of being very precise and quick in the end, but often at the price of becoming very rigid. A metamethodology needs to reduce this rigidity and aim at teaching not one method of thought, but several. Any systematic mistake of a method can thus be counteracted. Insufficient knowledge in one field can be made more stable and reliable by adding a net of knowledge from other areas. Just like Geertz (1972) suggested his net of history, different methods can enhance each other and explore areas, which otherwise would be considered too lofty to approach. Layers of history (Koselleck, 2003) are necessary for avoiding mistakes as well as advancing new ideas.

Furthermore, because the empirical genetic method is empirical, even more so than other methods, which make such claim for its artifacts, it in the end is more "simple" and direct in its results. "Practical theory" is not only a claim, but a requirement of the meta method itself.

What does that mean for history? In a genetic framework, history is a central element, not apart and by itself, but as a means, a tool, which enables genetic approaches. Some genetic approaches require history, some benefit from its help. Historical methods are thus one part of many methods, but an integral part.

\section{Acknowledgements}

I would like to thank my father Karl Hayo Siemsen for proofreading and Raffaele Pisano for the suggestion to this article.

\section{References}

Alexander of Aphrodisias (around 200/2014). On the Soul. Part 1: Soul as Form of the Body, Parts of the Soul, Nourishment and Perception. By V. Caston (Ed.). London: Bloomsbury.

Beneke, F. E. (1842). System der Logik als Kunstlehre des Denkens. Berlin: Dümmler.

Broadie, A. (1985). The Circle of John Mair. Logic and Logicians in Pre-Reformation Scotland. Oxford: Clarendon Press.

Einstein, A. (1916). Ernst Mach. Physikalische Zeitschrift, 17/7, 1st of April: 101-104.

Geertz, C. (1972). Deep Play. Notes on the Balinese Cockfight. Daedalus 101/1: 1-37.

Gimbutas, M. (1992). Die Ethnogenese der europäischen Indogermanen. Innsbruck: Innsbrucker Beiträge zur Sprachwissenschaft. Vorträge und Kleinere Schriften 54.

Haarmann, H. (2011). Das Rätsel der Donauzivilisation. Die Entdeckung der ältesten Hochkultur Europas. München: Beck.

Hadamard, J. (1945/1954). The Psychology of Invention in the Mathematical Field. New York: Dover.

Hattie, J. (2009). Visible Learning. A Synthesis of over 800 Meta-Analyses Relating to Achievement. London: Routledge.

Hattie, J. (2012). Visible Learning for Teachers. Maximizing Impact on Learning. London: Routledge.

Hotson, H. (2007). Commonplace Learning: Ramism and Its German Ramifications 1543-1630. Oxford: Oxford University Press.

Kessler, E. (2011). Alexander of Aphrodisias and His Doctrine of the Soul. 1400 Years of Lasting Significance. Early Science and Medicine, 16, 1-93. http://dx.doi.org/10.1163/9789004210196

Koselleck, R. (2003). Zeitschichten: Studien zur Historik. Frankfurt a. M.: Suhrkamp. 
Luchins, A. S. (1975). The Place of Gestalt Theory in American Psychology. In S. Ertel, L. Kemmler, \& M. Stadler (Eds.), Gestalttheorie in der Modernen Psychologie (pp. 21-44). Darmstadt: Steinkopff.

Luchins, A. S., \& Luchins, E. H. (1959). Rigidity of Behavior: A Variational Approach to the Effect of Einstellung. Eugene, Oregon, OR: University of Oregon.

Mach, E. (1905/1926/2002). Erkenntnis und Irrtum: Skizzen zur Psychologie der Forschung (5th ed.). Leipzig, Berlin: reprint by rePRINT.

Mach, E. (1905/1976). Knowledge and Error. Dordrecht: Reidel.

Mach, E. (1909). Erinnerungen an Darwin und die Entwicklungslehre. Anlässlich der Feier von Darwins hundertstem Geburtstage. Neue Freie Presse, 27 June 1909, 2.

Moleschott, J. (1852). Der Kreislauf des Lebens. Physiologische Antworten auf Liebig's Chemische Briefe. Mainz: Victor von Zabern.

Muir, E. (2007). The Culture Wars of the Late Renaissance: Skeptics, Libertines, and Opera. Cambridge, MA: Harvard University Press.

Peirce, C. S. (1878). How to Make Our Ideas Clear. Popular Science Monthly, 12, 286-302.

Siemsen, H. (2009). Conceptual Adaptation: Bridging Spatial and Temporal Relations by Cognitive Wormholes. In M. Albert et al. (Eds.), Transnational Political Spaces. Agents-Structures-Encounters. Frankfurt (M.): Campus.

Siemsen, H. (2010a). Alfred Binet and Ernst Mach: Similarities, Differences and Influences. University of Nancy, Revue Recherches \& Éducations, 3, 351-403.

Siemsen, H. (2010b). The Mach-Planck Debate Revisited: Democratization of Science or Elite Knowledge? Public Understanding of Science, 19, 293-310.

Siemsen, H. (2014). Ernst Mach: A Genetic Introduction to His Educational Theory and Pedagogy. In M. Matthews (Ed.), International Handbook of Research in History, Philosophy and Science Teaching (Vol. III, pp. 2329-2358). Frankfurt (M.): Springer.

Siemsen, H. (2015). The Transformation of Mind. Working Paper.

Siemsen, K. H. (2013). Learning by Gestalt. Gestalt Theory, 35, 155-168.

Thiele, J. (1978). Wissenschaftliche Kommunikation: Die Korrespondenz Ernst Machs. Kastellaun: Henn.

Vaney, V. (1911). Les classes pour arriérés. Recruitement, organisation, exercises d’orthopédie mentale. Bulletin de la Société libre pour l'Etude psychologique de l'Enfant, 73, 293-300.

Wertheimer, M. (1924/1938). Gestalt Theory. In W. D. Ellis (Ed.), A Source Book of Gestalt Psychology (pp. 1-11). London: Kegan, Trench, Trubner. 